\title{
Sounds of Stress: Assessment of Relationships between Ambient Noise, Vessel Traffic, and Gray whale Stress Hormone
}

Leila S. Lemos ( $\square$ leslemos@hotmail.com )

Oregon State University

Joseph H. Haxel

Oregon State University

Amy Olsen

Seattle Aquarium

Jonathan D. Burnett

Oregon State University

Angela Smith

Seattle Aquarium

Todd E. Chandler

Oregon State University

Sharon L. Nieukirk

Oregon State University

Shawn E. Larson

Seattle Aquarium

Kathleen E. Hunt

George Mason University

Leigh G. Torres

Oregon State University

\section{Research Article}

Keywords: glucocorticoids, stress, ocean noise, body condition, vessel traffic, gray whale

Posted Date: October 5th, 2021

DOl: https://doi.org/10.21203/rs.3.rs-923450/v1

License: (c) (1) This work is licensed under a Creative Commons Attribution 4.0 International License.

Read Full License 


\section{Abstract}

Elevated noise from human activities in nature can impact animal behavior and physiology, with subsequent impacts on individual health and population dynamics. Baleen whale communication, navigation, habitat use, and ability to recognize and locate prey and predators may be impaired by anthropogenic activities that increase ocean noise within the whales' hearing frequency range. To understand the physiological impacts of noise disturbance on baleen whales, we investigated the adrenal stress response of gray whales (Eschrichtius robustus) to variable ambient noise levels through an assessment of fecal glucocorticoid metabolite concentrations. This analysis was conducted at the individual level, at multiple temporal scales (1-7 days), and accounted for factors that may confound glucocorticoid hormone concentrations: sex, age, nutritional status, and reproductive state. Data were collected along the Oregon coast, USA, from June to October of 2016-2018. Results indicate a significant positive correlation between underwater noise levels and vessel traffic. Vessel counts from the day prior to fecal sample collection and sex had significant positive relationships with glucocorticoid metabolite concentrations. This study increases knowledge of gray whale physiological response to variable ocean noise and may inform management decisions regarding regulations of anthropogenic noise activities and thresholds near critical whale habitats.

\section{Introduction}

Since the 1960s, several habitats within the northeastern Pacific ocean, including deep basins and shelf edges, have become significantly louder ${ }^{1,2}$. This measured increase in ocean noise is primarily attributed to a dramatic rise in commercial shipping and vessel traffic ${ }^{3}$, with additional contributions from oil and gas exploration, naval sonar operations, seismic surveys, and recreational vessels $2,4,5$. Meanwhile, there is increasing evidence demonstrating that many marine biota are negatively impacted by these anthropogenic sound sources, including cephalopods and fish ${ }^{6,7}$, shrimps $^{8}$, crabs $^{9}$, and seals ${ }^{10}$. Moreover, impacts of modified ocean soundscapes have also been demonstrated in cetaceans ${ }^{4,7,11}$, which are some of the most acoustically sensitive species in the marine environment as they rely on sound for multiple critical life functions including communication, foraging, and navigation ${ }^{11}$. Elevated ocean noise has been correlated with changes in cetacean distribution ${ }^{12}$, calling rates ${ }^{7,11,13}$, and behavior ${ }^{14,15}$. However, despite broad recognition of the need to understand the influence of ocean noise on cetacean physiology ${ }^{16}$, only a few studies have addressed this issue ${ }^{17,18}$.

Concerns regarding chronic impacts of ocean noise on the physiology and vital rates of cetaceans engendered the Population Consequences of Disturbance $\left(\mathrm{PCoD}^{16}\right)$ and Population Consequences of Multiple Stressors (PCoMS ${ }^{19}$ ) frameworks that are aimed at linking the chronic effects of noise disturbance on individual cetacean physiology with subsequent impacts on population trends. These frameworks evaluate internal factors that affect individual fitness and homeostasis to describe impacts on individual health and vital rates, which, when aggregated over all exposed individuals, may impact population dynamics ${ }^{16,17,19-23}$. Therefore, variation of individual physiological responses to disturbance 
events can contribute to population declines ${ }^{24}$, making assessment of individual cetacean physiology an informative approach to population management, policy decisions and conservation efforts ${ }^{20,25}$. While evaluation of baleen whale physiology can be challenging, multiple studies have reliably correlated various anthropogenic impacts with physiological responses, including shifts in energy balance ${ }^{24}$, deterioration in body condition and overall health ${ }^{26-28}$, increases in stress-associated hormones ${ }^{17,24,29,30}$, decreases in reproductive hormones ${ }^{31}$, depressed immune responses ${ }^{32}$ and even mortality ${ }^{32,33}$. However, data remain deficient on the physiological impacts on baleen whales from chronic exposure to anthropogenic ocean noise, which may have significant effects on population trends.

Baleen whales are particularly vulnerable to impacts from low frequency noise caused by vessel propeller cavitation because it overlaps with the low frequencies these whales primarily use for communication ${ }^{34,35}$. Such frequency overlap can cause "acoustic masking", potentially hindering the ability of whales to communicate, navigate or forage ${ }^{11}$, and creating a loss of communication space, all of which may increase the stress response in exposed whales ${ }^{16}$. Evaluation of "whale stress" is challenging given difficulty in sample collection ${ }^{31}$, but non-invasive collection of fecal samples for hormone assessment has proven to be a reliable technique to monitor baleen whale physiology $29,30,36$.

Glucocorticoids (GCs; e.g., cortisol, corticosterone) are adrenal steroid hormones that coordinate an adaptive physiological response ("stress response") in vertebrates to homeostatic challenges, increasing in circulation within minutes of exposure to a wide variety of stressors, including ambient noise ${ }^{17,37,38}$. These hormones are eventually cleared from circulation by the liver and excreted via the feces ${ }^{39}$. GC metabolites tend to increase in concentration in feces hours or days after the stress exposure, with the time lag determined by species-specific gut passage time ${ }^{39,40}$. Thus, fecal GCs (fGC) can be used to monitor the physiological responses to acute noise exposure provided the appropriate time lag to excretion can be determined (often 1 to 2 days in large mammals ${ }^{40}$ ).

Studies in several terrestrial mammals (e.g., elk, Cervus elaphus; wolf, Canis lupus ${ }^{41}$ ) and avian species have correlated anthropogenic noise to increases in $\mathrm{fGCs}^{42,43}$, but such data are rarely available for baleen whales. A single study has correlated population-level decreases in fGC concentrations of North Atlantic right whales (Eubalaena glacialis) with decreased ship traffic and underwater noise from before to after the events of 11 September $2001^{17}$.

Multiple factors can confound assessment of hormone concentrations in feces ${ }^{44-46}$, such as sex, age, nutritional status, reproductive state, and environmental factors (e.g., temperature ${ }^{38}$ ), all of which should be accounted for at an individual level to reliably relate whale GCs to an anthropogenic disturbance. Hence, in this study, we aim to better understand how individual baleen whales physiologically respond to ambient noise and vessel traffic while controlling for multiple confounding factors. We investigate correlations between variable ambient ocean noise and vessel traffic levels, and then determine the effects of vessel traffic and other confounding variables on fGC concentrations in Eastern North Pacific gray whales (Eschrichtius robustus) sampled along the coast of Oregon, United States. Our objectives are 
to (1) describe the relationship between vessel counts leaving the ports each day with Sound Pressure Levels (SPL) recorded by a hydrophone outside the port entrance, (2) investigate potential correlations between ambient noise levels and fGC in simultaneously collected gray whale fecal samples, (3) determine the effects of vessel traffic and potential confounding variables (i.e., body condition, age, sex, time) on gray whale $\mathrm{fGC}$ concentrations, and (4) determine the time lag between acute noise exposure and $\mathrm{fGC}$ concentration response in gray whales, which likely represents the gut passage time. We hypothesize a correlation between ambient noise levels and vessel traffic and predict that both ambient noise levels and vessel traffic will be positively correlated with gray whale fGC concentrations. Given the data deficiency regarding physiological impacts of ocean noise on baleen whales, this study addresses a critical knowledge gap that may inform acoustic disturbance policies regarding how exposure to anthropogenic noise may impact the physiology and population dynamics of baleen whales.

\section{Results}

We analyzed 1,128 hours of acoustic recordings from a total of 235 days during the 2017-2018 seasons. In addition, 411 days of vessel count data during the 2016-2018 field seasons were analyzed.

Furthermore, a total of 53 gray whale fecal samples were collected from 14 different mature females (35 samples) and 13 different mature males (18 samples) (Fig. 1; Appendix S1: Fig. S1). Five fecal sample concentrations were $<$ LOD for progestin metabolites ( $\mathrm{PP}$ ) and ten for androgen metabolites (fA), while 19 fecal samples had no corresponding BAI information. Therefore, these samples had missing values (NA) in the LMM analyses for the respective variables. In total, we had variable sample sizes by year and sex (males: 0 in 2016, 5 in 2017, and 13 in 2018; females: 6 in 2016, 9 in 2017, and 20 in 2018).

Photo-identification analysis of the 53 gray whales sampled in this study indicated that the mean number of days a whale was resident in the area prior to sampling was $32.96(S D=39.57, \min =0, \max =120)$. Despite the large SD and that 20 individuals were not observed in our study system prior to the day of sample collection ( $\min =0$ ), an assessment of the total number of days sampled whales were observed in our study region across the whole sampling year also indicates high residency time (mean $=59.07, \mathrm{SD}$ $=42.51$, $\min =1, \max =125)$, with only six whales observed on one day per year $(\min =1)$. It is important to highlight that (1) a whale could have been in the study area before first recorded by our team, and (2) a whale may have left the study area after we first observed it in a year and then return. Overall, these results demonstrate high residency time of sampled whales within the study area and are therefore likely exposed to the noise, wind and vessel data assessed in this study.

Daily vessel counts from the two ports were highly variable, ranging from 0 to 521 vessels counted per day, with higher mean numbers of vessels in July $(n=135)$ and August $(n=133)$. Underwater noise levels were positively correlated with vessel counts (2017: rate of change $=0.020, F_{1,114}=43.72, R^{2}=0.271, p<$ $0.001 ; 2018$ : rate of change $=0.016, F_{1,112}=54.92, R^{2}=0.323, p<0.001 ;$ Fig. $\left.2 A\right)$. A majority of whales were sampled within $10 \mathrm{~km}$ of the hydrophone ( $44.62 \%<5 \mathrm{~km} ; 15.38 \%$ between $5-10 \mathrm{~km} ; 40 \%>10 \mathrm{~km})$, indicating likely exposure to the vessel traffic and recorded noise levels. 
Daily median wind speed also fluctuated, ranging from 0.7 to $13.5 \mathrm{~m} / \mathrm{s}$, with higher median wind speeds occurring in July $(5.95 \mathrm{~m} / \mathrm{s})$ and August $(5.9 \mathrm{~m} / \mathrm{s})$. No correlation between wind speed and noise levels was observed in 2017 (rate of change $=0.146, F_{1,114}=1.201, R^{2}=0.002, p=0.275$ ) or 2018 (rate of change $=-0.012, F_{1,81}=0.006, R^{2}=-0.012, p=0.937$; Fig. 2B). Visual assessment of the temporal patterns in ambient sound level variation during the study periods (Fig. 3 ) indicates strong peaks in underwater noise between 6 and 8 a.m. most days, coincident with low median wind speeds. Yet, this morning time period corresponds with peak recreational vessel traffic as boats transit out the harbor to fishing grounds. Wind speeds in this study system typically begin to rise after $10 \mathrm{a} . \mathrm{m}$. and peak between 3 and 4 p.m., which is an incongruous pattern with recorded ambient noise levels.

Subsequent $\mathrm{LMM}$ analyses identified the best overall model explaining fGC data as including vessel count from the previous day, sex, year, BAl, and fP and fA concentrations (Table 1, Model 2; AIC $=57.91$, $\left.d f=12, R^{2} m=0.33, R^{2} c=0.92\right)$, with vessel counts from previous day $\left(F_{1,11}=4.93, p<0.05\right.$; Fig. $\left.4 A\right)$ and sex $\left(F_{1,11}=9.95, p<0.01\right)$ both significant (Table 2). Once the most influential temporal scale of vessel counts on $\mathrm{fGC}$ was determined (e.g., previous $24 \mathrm{hrs}$ ), eight additional LMMs were run with varied combinations of the fixed effects (Table 1, A-H), but model 2 still displayed the lowest AIC.

Table 1

Linear mixed model (LMM) selection parameters of gray whale fecal glucocorticoid metabolite (fGC) concentrations relative to vessel counts, sex, year, progestin metabolites ( $f P$ ), androgen metabolites ( $f A$ ) and body condition (Body Area Index: BAI). All models used whale identification (whale ID), day of the year (DOY) and month as random factors to account for pseudoreplication and variations in sampling per day and month, respectively. Models 1-8 included the same predictor variables except vessel counts, which was assessed at different temporal scales in each model and ranged from the count of vessels on

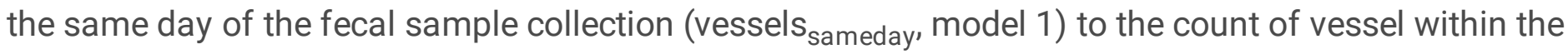
seven previous days (vessels prev7sum, model 8). Once the most influential temporal scale for vessel counts was determined (i.e., previous day), eight additional LMM were run with varied combinations of the fixed effects (stepwise process, models A-H; below the thin black line). Model in bold represents the selected model based on the lowest Akaike Information Criterion (AIC). The degrees of freedom for each model are indicated by DF. The fit of each model is represented by the marginal $R^{2}\left(R^{2} m\right.$; variance explained by fixed effects) and the conditional $R^{2}\left(R^{2} c\right.$; variance explained by both fixed and random effects). 


\begin{tabular}{|c|c|c|c|c|}
\hline Models & DF & AIC & $\mathbf{R}^{2} \mathbf{m}$ & $\mathbf{R}^{2} \mathbf{c}$ \\
\hline 1) $f G C \sim$ vessels sameday + sex + year $+f P+f A+B A I+(1 \mid$ whale ID $)+(1 \mid D O Y)+(1 \mid$ month $)$ & 12 & 61.35869 & 0.19 & 0.91 \\
\hline 2) $f G C \sim$ vesselsprev $1+$ sex + year $+f P+f A+B A I+(1 \mid$ whale ID $)+(1 \mid D O Y)+(1 \mid$ month $)$ & 12 & 57.91271 & 0.33 & 0.92 \\
\hline 3) $\mathrm{fGC} \sim$ vesselsprev2sum + sex + year $+f P+f A+B A I+(1 \mid$ whale ID $)+(1 \mid D O Y)+(1 \mid$ month $)$ & 12 & 58.08519 & 0.32 & 0.92 \\
\hline 4) $f G C \sim$ vesselsprev3sum + sex + year $+f P+f A+B A I+(1 \mid$ whale ID $)+(1 \mid D O Y)+(1 \mid$ month $)$ & 12 & 59.08652 & 0.30 & 0.88 \\
\hline 5) $f G C \sim$ vesselsprev4sum + sex + year $+f P+f A+B A I+(1 \mid$ whale ID $)+(1 \mid D O Y)+(1 \mid$ month $)$ & 12 & 59.89063 & 0.21 & 0.88 \\
\hline 6) $f G C \sim$ vesselsprev5sum + sex + year $+f P+f A+B A I+(1 \mid$ whale ID $)+(1 \mid D O Y)+(1 \mid$ month $)$ & 12 & 59.31529 & 0.24 & 0.91 \\
\hline 7) $\mathrm{fGC} \sim$ vesselsprev6sum + sex + year $+f P+f A+B A I+(1 \mid$ whale ID $)+(1 \mid D O Y)+(1 \mid$ month $)$ & 12 & 59.40798 & 0.23 & 0.91 \\
\hline 8) $\mathrm{fGC} \sim$ vesselsprev7sum + sex + year $+\mathrm{fP}+\mathrm{fA}+\mathrm{BAI}+(1 \mid$ whale ID $)+(1 \mid \mathrm{DOY})+(1 \mid$ month $)$ & 12 & 59.56694 & 0.22 & 0.89 \\
\hline A) $f G C \sim$ vessels $s_{\text {prev } 1}+$ sex + year + fP + fA + (1| whale ID $)+(1 \mid D O Y)+(1 \mid$ month $)$ & 11 & 91.99289 & 0.19 & 0.33 \\
\hline B) $f G C \sim$ vessels srev1 + sex + year + fP + (1| whale ID $)+(1 \mid D O Y)+(1 \mid$ month $)$ & 10 & 98.64120 & 0.19 & 0.19 \\
\hline C) $f G C \sim$ vesselsprev1 + sex + year + (1|whale ID $)+(1 \mid D O Y)+(1 \mid$ month $)$ & 9 & 105.55485 & 0.09 & 0.09 \\
\hline D) $\mathrm{fGC} \sim$ vesselsprev1 $+\mathrm{sex}+(1 \mid$ whale ID $)+(1 \mid \mathrm{DOY})+(1 \mid$ month $)$ & 7 & 101.52082 & 0.05 & 0.05 \\
\hline E) fGC vesselsprev1 $+(1 \mid$ whale ID $)+(1 \mid D O Y)+(1 \mid$ month $)$ & 6 & 99.57796 & 0.01 & 0.01 \\
\hline F) $\mathrm{fGC} \sim$ vessels $_{\text {prev1 }}+$ sex + year $+\mathrm{fP}+\mathrm{BAI}+(1 \mid$ whale ID $)+(1 \mid \mathrm{DOY})+(1 \mid$ month $)$ & 11 & 66.03426 & 0.50 & 0.50 \\
\hline G) $\mathrm{fGC} \sim$ vessels prev $1^{+}$sex + year $+\mathrm{fA}+\mathrm{BAI}+(1 \mid$ whale ID $)+(1 \mid \mathrm{DOY})+(1 \mid$ month $)$ & 11 & 60.98693 & 0.32 & 0.91 \\
\hline H) $\mathrm{fGC} \sim$ vessels prev $1^{+}$sex + year + BAI + (1| whale ID $)+(1 \mid \mathrm{DOY})+(1 \mid$ month $)$ & 10 & 68.88837 & 0.47 & 0.48 \\
\hline
\end{tabular}

Table 2

Parameter estimates from the chosen generalized linear mixed model (model 2) for gray whale fecal glucocorticoid metabolite concentrations using vessel counts from the previous day, sex, year, progestin metabolites, androgen metabolites, and body condition (Body Area Index: BAI) as fixed effects and whale identification, day of the year and month as random factors. Asterisks indicate significance $(p<0.05)$.

\begin{tabular}{|llll|}
\hline Fixed Effects & Estimate & SE & p value \\
\hline Vessel counts from the previous day & 0.289 & 0.130 & $0.04{ }^{*}$ \\
\hline Sex & -0.413 & 0.131 & $0.00{ }^{*}$ \\
\hline Year (2017) & 0.435 & 0.424 & 0.330 \\
\hline Year (2018) & 0.393 & 0.421 & 0.371 \\
\hline Progestin metabolites & 0.172 & 0.111 & 0.142 \\
\hline Androgen metabolites & -0.095 & 0.045 & 0.062 \\
\hline Body Area Index & -0.047 & 0.028 & 0.120 \\
\hline
\end{tabular}

Linear regression between $\mathrm{fGC}$ concentration and vessel count of previous day, partitioned by sex, indicated no significant correlation ( $p>0.05$; Fig. 4B), though a positive trend in males is visually evident.

Linear regressions directly assessed the role of sex on the relationship between ambient noise and whale stress (2017-2018 data only). Female fGC concentrations showed no significant correlation with ambient noise levels, but male fGC concentrations were positively correlated with daily SPL from the previous day in 2018 (rate of change $=12.06, F_{1,10}=5.93, R^{2}=0.31, p<0.05$ ), but not in 2017 ( $p>0.05$; Fig. 5), which may be related to a larger sample size of fecal samples from males in $2018(n=13)$ compared to 2017 ( $n$ 
=5). No significant difference was found between whale sex and distance to the nearest port (2016-2018 data; $\mathrm{n}=531$, Mann-Whitney: $\mathrm{p}>0.05$ ).

\section{Discussion}

This study marks the first-time baleen whale fGC concentrations have been related to ocean noise conditions at an individual level. We accomplished this through a strong proxy correlation between variable ambient noise levels and vessel counts from nearby ports, and subsequently demonstrated a significant positive correlation between fGC concentrations in male whales and increased vessel counts and noise levels during the previous 24-hour period. Our assessment of the relationship between whale stress and vessel counts occurred at varied temporal scales and accounted for confounding factors potentially influencing ambient sound levels (i.e., wind) and whale fGC concentrations, (i.e., body condition as an indicator of nutritional state, year, sex, age, and reproductive hormone concentrations). The amount of vessel traffic, and not wind speed, is correlated with underwater sound levels in our nearshore study area, implying that vessel traffic is the primary contributor to ambient noise and, thus, a contributing factor in the physiological response of whales.

With increased ocean use, and hence increased sources and levels of anthropogenic disturbance to cetaceans, our findings provide environmental managers with needed information on the consequences of elevated ambient noise on cetacean physiology, which could ultimately be applied in the PCoD and PCoMS frameworks to estimate impacts on population dynamics. Furthermore, this study highlights the utility of combining information on internal drivers (i.e., BAl, reproductive hormones) with external drivers (i.e., noise, year) of mammalian "stress response", since all these variables are known to affect physiological responses to acute stressors. Given the significant correlation between $\mathrm{FGC}$ and BAI in gray whales ${ }^{46}$, it was particularly important to include this nutritional index in our assessment of stress response. By incorporating multiple factors potentially impacting animal physiology into a single analysis, the "noisiness" of fecal hormone data can resolve to provide a clearer picture of the major factors that affect stress responses in a field setting. While many questions remain regarding the drivers, timing, and repercussions of variable baleen whale hormone concentrations, we have demonstrated the feasibility of these methods and the correlation between noise and whale stress response.

Our analysis detected a statistically significant difference in $\mathrm{fGC}$ response to vessel counts and ambient noise levels by year (significant in 2018, which may be associated with a larger sample size in 2018), and by sex (significant for males). We propose two potential explanatory hypotheses for the sex difference. First, reproductively active males may rely more on acoustic signaling, thus causing male gray whales to be more sensitive to vessel presence and elevated background noise levels than females. Competitive reproductive male behavior ${ }^{47}$ and higher androgen metabolite concentrations ${ }^{29}$ have been previously documented for this population. Furthermore, fGC concentrations in reproductively active males may already be elevated due to reproductive competition ${ }^{29,30,48}$, rendering vessel traffic and ocean noise as an additive factor to $\mathrm{fGC}$ concentrations in males ${ }^{29}$. Second, males may be predisposed to using habitat within this study area with higher levels of vessel traffic (i.e., near ports) than females. Yet, our 
assessment of sex-specific spatial distribution patterns using all sightings data from 2016-2018 revealed that males were not encountered closer to ports than females, making the first hypothesis more likely.

We assessed the influence of eight different temporal scales (between noise exposure and fecal collection) of vessel counts on gray whale fGC concentrations and determined that vessel count on the day prior to sample collection best explained fGC data. Thus, we hypothesize that gut transit time of stress hormones in gray whales may occur within 24 hours of the disturbance event. We recognize that whales likely moved location within the 24 hours prior to fecal sample collection, but these whales were not tagged, so we are unable to quantify the exact sound exposure level of individual whales in the days prior to sample collection. However, our non-invasive photo-identification analysis indicates that most whales have high residency time in the study region and therefore were likely exposed to the measured noise and vessel traffic or very similar levels encountered in the study area. Our approach to summarize and assess vessel traffic and noise levels across the whole study area on each day assumes all whales within the study area endure a common noise and vessel exposure level each day regardless of location. Yet, unaccounted for whale movement across the study area may obscure finer-scale relationships between variation in local noise exposure and later excretion of GCs, potentially reducing correlations for longer time lags. However, our results align with previous studies indicating that large mammals generally have gut transit times between 12 hours and 4 days, with a 24 hour lag common in large carnivores ${ }^{17,29,40}$.

A complete understanding of the impact of vessel-related noise on whale physiology remains unclear, and factors unaccounted for in this study may influence gray whale GC concentrations, such as contaminants ${ }^{49}$, predation events ${ }^{50}$, and infections ${ }^{51}$. Vessel traffic can affect whale physiology via multiple pathways, including elevated ambient sound levels that may cause increased energetic expenditure to call more loudly or acoustic masking of signals from conspecifics and predators, behavioral disturbance from vessel traffic, increased risk of collision with vessels, or a combination of these and other possibilities. This population of gray whales does show signs of propeller strike ${ }^{29}$ and is also subject to whale watch activities with documented behavioral disturbance from vessel traffic within our study region ${ }^{52}$. Thus, disentangling the impacts of elevated noise from other impacts of vessel traffic will require further assessment and larger sample sizes.

Although the vessel count data used in this study summarizes most of the vessel traffic in our study region, Newport and Depoe Bay support many large commercial fishing vessels and approximately five whale watch operations, and Newport has frequent harbor dredging during summer months and is home to the NOAA Pacific Fleet of large research vessels. All these vessel activities were not included in the vessel count data, yet most commercial fishing vessels and the large research vessels do not overlap with gray whale habitat once they are beyond the harbor due to more offshore destinations ( $L$. Torres, pers $o b s)$. This unaccounted-for vessel traffic may partly explain the variation in data points around the trend lines between daily ambient sound levels and vessel counts (Fig. 2) and the unexplained variance in the linear model. Therefore, future efforts should attempt to directly correlate recorded ambient ocean noise 
levels with whale $\mathrm{GC}$ concentrations, similar to our linear regressions between noise levels on the previous day and GC concentrations.

Life within noisy environments can be stressful for many mammals ${ }^{17,53}$, and often correlates with deterioration in overall health $24,26,28$, depressed immune systems and mortality ${ }^{32}$. In the marine environment, sound is a primary sensory mechanism and critical for the life functions of acoustically sensitive cetaceans. Here we demonstrate for the first-time correlations between ambient ocean noise levels, vessel counts, and whale stress-related hormone concentrations at an individual level and within short temporal periods ( 24 hours). Our gray whale case study results can inform how other, less accessible baleen whale populations may respond to disturbance, and enable progress within the PCoD and PCoMS frameworks to understand physiological impacts of ocean noise on baleen whale populations. Future work should build upon these documented associations between ambient noise levels and stress responses in baleen whales to assess impacts on individual vital rates and subsequent population dynamics. With continued assessment of physiological impacts of ocean noise on baleen whales, environmental managers can develop effective regulations, such as sound level thresholds near whale habitats, to mitigate impacts on vulnerable and protected whale populations.

\section{Methods}

\section{Gray whale data}

All methods were carried out in accordance with relevant guidelines and regulations. This project was approved by the Oregon State University Institutional Animal Care and Use Committee (IACUC-2019-0008) and complies with the ARRIVE guidelines. All gray whale data collection was carried out under a research permit from NOAA/NMFS (\#16011 and \#21678, issued to John Calambokidis).

We used a small research vessel (5.4 m rigid-hulled inflatable boat) to collect gray whale data over the course of three foraging seasons (May to October from 2016-2018) along the central coast of Oregon, USA, including near the ports of Newport and Depoe Bay (Fig. 1). Whale photographs were taken for individual photo-identification and drone-based videos were recorded for photogrammetry analysis when weather conditions and whale behavior were suitable (methods are fully described $\mathrm{in}^{54}$ ). We also opportunistically collected fecal samples at the whale sightings using two $300 \mu \mathrm{m}$ nylon mesh dipnets (methods are fully described $\mathrm{in}^{29}$ ). Samples were transferred to sterile plastic jars and placed on ice until stored in a freezer $\left(-20^{\circ} \mathrm{C}\right)$ for later analysis. Date, time, and location were documented for each fecal sample, as well as the matching photo for the specific individual.

We used Adobe Bridge software (version 8.0.1.282) for photo-identification analysis. Photographs were compared to long-term gray whale catalogs held by the Marine Mammal Institute at Oregon State University and Cascadia Research Collective (Olympia, WA, USA) to obtain individual sex and minimum age information based on date of first sighting. If sex was unknown, sex was determined through fecal genetic analyses (methods are fully described in ${ }^{28}$ ). Given the unknown movements of our study whales 
prior to fecal sample collection, we assessed the residency time (in days) of these whales within the study area to justify our assumption that the whales were exposed to the measured soundscape levels and vessel counts. Through photo-identification comparison, we summed the number of days a sampled whale was in the study area (1) prior to sample collection in that year, and (2) in total that year.

Images of whales flat and straight at the surface were extracted from drone video recordings using VLC software (version 2.2.8) and scored as good or poor quality based on pre-defined attributes ${ }^{28}$. Only images scored as good were measured in custom MATLAB (version 9.3.0.7, release 2017b) software, producing a series of ten morphometric attributes that describe the whale's body condition. These metrics were assessed in R (version 3.5.055) to calculate a final metric called Body Area Index (BAI), which is a unitless and length-standardized metric of body condition that allows comparisons among individuals of different lengths and demographic units (e.g., calves and adults, or males and females ${ }^{28}$ ). We applied a coefficient of variance threshold of $5 \%$ for both whale length and BAI measurements to improve accuracy. Whales were assigned to a demographic unit based on sex and maturity status in each year ${ }^{28}$ based on fieldwork observations, photo-identification, and photogrammetry results. The BAI metric has been successfully implemented to document variation in body condition in this specific gray whale population across foraging seasons ${ }^{28}$.

Fecal samples were filtered, desalted, and freeze-dried ${ }^{29}$. Dried, processed samples were mixed and weighed to the nearest $0.2 \mathrm{~g}$; samples below $0.02 \mathrm{~g}$ were excluded from the analysis to avoid inflated values ["small sample effect"; see 33,43]. Fecal hormone metabolites were extracted ${ }^{29}$ and quantified using commercial Enzyme-linked Immunosorbent Assay kits for cortisol (\#ADI-900-071), progesterone (\#ADI-900-011), and testosterone (\#ADI-900-065) from Enzo Life Sciences, following the manufacturer's protocols (https://www.enzolifesciences.com). Since fecal samples reflect the metabolized products of the parent hormones, the cortisol kit quantifies $\mathrm{fGC}$, the progesterone kit quantifies progestin metabolites $(\mathrm{fP})$, and the testosterone kit quantifies androgen metabolites (fA).

Samples were run in duplicate in 2016-2017, and in triplicate in 2018. All samples were analyzed within 11 months of collection. Our quality assurance and quality control protocols include full standard curves in each assay, re-run of any sample with $>15 \%$ coefficient of variation (CV) between replicates, and re-run of any sample outside the percent-bound range of $15-85 \%$. Samples not conforming to these standards were analyzed again until suitable values were obtained. Values below the limit of detection ( $\angle L O D)$ were excluded from the analysis ${ }^{57}$. When multiple fecal samples were collected from the same individual in the same day, we applied the values from the sample with higher mass ${ }^{56}$. Gray whale fecal hormone assays have been validated for all hormones described in this study, and results exhibited excellent parallelism and accuracy as well as good match to known physiological state (age, sex, reproductive state $)^{29}$.

\section{Acoustic data}


Concurrent with gray whale data collection, acoustic data were recorded off the coast of Newport, Oregon, from 15 June to 8 October of 2017 and 5 June to 1 October of 2018 (no acoustic data is available from 2016). A passive acoustic monitoring (PAM) hydrophone system was deployed outside the Newport harbor entrance at $44.5932 \mathrm{~N},-124.1029 \mathrm{~W}$, in $20 \mathrm{~m}$ water depth, and $1.25 \mathrm{~km}$ from the coastline (Fig. 1). The custom PAM system consisted of an omni-directional hydrophone (International Transducer Corporation transducer model ITC1032) with sensitivity - $192 \mathrm{~dB}$ re $\mu \mathrm{Pa} \mathrm{V}^{-1} @ 1 \mathrm{~m}$ combined with a lowpower 16-bit data acquisition system and preamplifier housed in a fiberglass composite pressure housing ${ }^{58}$. The PAM system was mounted on a weighted, semi-trawl protected aluminum frame $0.5 \mathrm{~m}$ above the seafloor with no sea surface expression. Data were recorded at $32 \mathrm{kHz}$ sample rate on a $20 \%$ duty cycle (12 minutes of every hour). A low frequency cutoff was applied to avoid aliasing around the Nyquist frequency, resulting in acoustic measurements that included energy up to $13 \mathrm{kHz}$. Data analysis followed previously described methods ${ }^{58}$. Root mean square $(\mathrm{rms})$ sound pressure levels (SPL) were calculated from $50 \mathrm{~Hz}-1,000 \mathrm{~Hz}$ frequency band. This frequency range captures low frequency vesselgenerated noise $<1,000 \mathrm{~Hz}$ typical of vessels using the ports of Newport and Depoe Bay ${ }^{59}$, and the sound energy from wind-related processes with a lower bound of $400 \mathrm{~Hz}{ }^{60}$ while avoiding the peak of surface wind noise near $8,000 \mathrm{~Hz}$. This range is also relevant for the acoustic sensitivity of gray whales and overlaps with their most frequent call observed in the northeastern Pacific (known as "M3 call") ${ }^{61-63}$. A daily median rms sound pressure level (SPL; $50 \mathrm{~Hz}-1 \mathrm{kHz})$ calculated from 6 a.m. to 7 p.m. Pacific Daylight Time provides a measure of the $50^{\text {th }}$ percentile, or typical sound levels, associated with vessel activity at the harbor entrance during the busiest daytime hours of each day.

\section{Vessel traffic data}

Daily vessel counts at the ports of Newport and Depoe Bay during our three field seasons were obtained from the Oregon Department of Fish and Wildlife (ODFW) through video analysis at the ports. These daily vessel counts consist only of recreational craft, including commercial charters on fishing and crabbing trips, and private boats (e.g., private fishing trips, kayaks, row boats, and jet skis). Therefore, vessel activity for other purposes (e.g., whale watching, research, funerals, maintenance trips, commercial fishing, Coast Guard, and dredging) are not tracked by these counts and thus, are not accounted for in this analysis. However, during the time period of this study, no major seismic, sonar or marine construction occurred in our study area, and recreational vessel traffic in coastal areas has been found to correlate strongly with ambient noise levels ${ }^{5,7}$.

\section{Wind speed data}

Wind-generated surface noise also contributes to ocean soundscapes ${ }^{64}$. Therefore, we compiled local wind speed data during our study periods to assess and compare the contributions of wind and vessel traffic to recorded underwater ambient noise levels. Hourly wind speed data from an anemometer station located near the hydrophone on the South Beach jetty entrance to the port of Newport (station NWPO3, 
Newport, OR, -44.613 N, 124.067 W; Fig. 1) during our three field seasons were obtained from the NOAA National Data Buoy Center (NDBC). Times were converted to local Pacific Daylight Time. Hourly median wind speed $(\mathrm{m} / \mathrm{s})$ and a daily median wind speed value $(\mathrm{m} / \mathrm{s})$ from 6 a.m. to 7 p.m. were calculated to match noise level measurements from the deployed hydrophones.

\section{Data analysis}

Our goal was to assess if and how gray whale fGC concentrations vary relative to vessel counts as a proxy for ambient ocean noise conditions, while simultaneously accounting for the effects of year, demographic unit, other hormone metabolites, and body condition (BAI). Therefore, every fecal sample was matched with the BAI measurement of that individual from the same day or within \pm 14 days of the fecal sample collection (no change in body condition within this window was detected; paired t-test using all BAI values of individuals assessed within 14 days in 2016, 2017 and 2018: $n=61, p=0.86, d f=60, t=$ - 0.174).

Only mature males and non-pregnant, non-lactating mature females were included in this analysis to minimize the known impact of normal variation in fGC concentrations due to life history phases 29,30,65. All statistical analyses were conducted in R software ${ }^{55}$ with a significance level of 0.05 . Normality of all variables was tested using the Shapiro-Wilk normality test, with non-normal variables log-transformed (log-normal [value +1]) before further analysis.

Linear regressions were performed using the $/ m$ function in $\mathrm{R}$ to test for correlations between (1) ambient noise (daily median SPL $\mathrm{rms}_{\mathrm{rms}}$ ) in 2017 and 2018 and daily vessel count data from both ports, and (2) ambient noise in 2017 and 2018 and daily median wind speed. To further explore the temporal patterns in underwater sound levels and correlation with local wind patterns, the median noise levels for each hour of each day recorded by the Newport hydrophone $(50 \mathrm{~Hz}-10,000 \mathrm{~Hz})$ in 2017 and 2018 were plotted in MATLAB (version 9.7.0.1190202 - R2019b) alongside the hourly median wind speed over the same time period (Fig. 3).

Once the relationship between ambient noise and vessel counts was established (Fig. 2), and analyses of wind speed data indicated wind was not the dominant source of underwater noise, (Fig. 3), we conducted linear mixed models (LMM), using the Ime4 package in $\mathrm{R}^{66}$, to assess the effects of vessel counts, year, demographic units, BAl, and other hormone metabolites on $\mathrm{fGC}$ concentrations. Hence, we use vessel counts as a proxy of ambient noise exposure. This approach allows us to use whale data collected in 2016 when a hydrophone was not deployed concurrently with whale data collection. The ports of Newport and Depoe Bay are $22 \mathrm{~km}$ apart, which is within the daily travel range of a gray whale. As daily vessel counts at Newport and Depoe Bay were positively correlated (rate of change $=3.176, F_{1,233}=$ $520.6, R^{2}=0.689, p<0.001$ ), we assumed that vessel activity from both ports influences acoustic conditions within the study area. Therefore, we summed vessel counts from the two ports for analysis relative to $\mathrm{fGC}$ concentrations. 
Due to uncertainty regarding gut transit time (which cannot be determined experimentally in mysticetes ${ }^{40}$ ), different time lags between vessel count and fecal collection were assessed in the LMMs, including the sum of vessel counts on the same day as fecal sample collection, and on the previous 1-7 days (based on known gut transit times in large mammals of $\sim 12$ hours to 4 days ${ }^{39,67,68}$ ). All models included the whale identification, day, and month as random effects to account for pseudoreplication and variations in sampling per day and month, respectively. Model selection was based on the lowest Akaike's information criterion $\left(\mathrm{AIC}^{69}\right)$. After the most influential temporal scale for vessel counts was determined, additional LMMs were run with varied combinations of the fixed effects. Model fit was evaluated by assessing the marginal $R^{2}\left(R^{2} m\right.$ : variance explained by fixed effects) and the conditional $R^{2}\left(R^{2} c\right.$ : variance explained by both fixed and random effects) using the MuMIn package in $\mathrm{R}^{70,71}$. F-statistics and $\mathrm{p}$-values were obtained using the ImerTest package ${ }^{72}$. Additional linear regressions between $\mathrm{fGC}$ concentrations and factors identified as significant in the LMMs were conducted as post-hoc analyses to verify linear correlations and describe the direction of the association.

In an effort to directly assess the impact of variable ambient noise levels on gray whale stress responses, without the intermediary of vessel counts, we conducted additional linear regressions between fGC concentrations and acoustic levels. For these analyses we had a smaller sample size based on only 2017 and 2018 data because no hydrophone data were available for 2016.

Sex specific spatial distribution patterns may have pre-disposed a demographic group to different noise exposures (e.g., closer to ports). Hence, to assess any sex specific distribution pattern relative to distance from port, the Euclidean distance between the initial whale sighting and the nearest port (Newport or Depoe Bay) was calculated using ArcGIS (version 10.8) for all whale sightings in this project (2016-2018). A Mann-Whitney $\mathrm{U}$ test was used to compare the difference in distance to port by whale sex.

The code and associated data to run the LMMs, linear regressions and Mann-Whitney $U$ test are deposited in the Dryad Digital Repository: http://doi.org /10.5061/dryad.n5tb2rbvn ${ }^{73}$.

\section{Declarations}

\section{Acknowledgements}

This work was supported by the NOAA National Marine Fisheries Service Office of Science and Technology Ocean Acoustics Program [2016 and 2017; 50-27], and the Oregon Sea Grant Program Development funds [2018; RECO-40-PD]. We are thankful for the support of Brazil's Science Without Borders program, Brazil's CNPq, and the Harvard Laspau Institute for financial aid and academic advising to LSL. We are also thankful for the support of the Mamie Markham Research Award (Hatfield Marine Science Center/OSU) and Cetacean Society International for awards given to LSL to support data and laboratory analyses. We thank the NOAA Pacific Marine Environmental Laboratory Acoustic Program for hydrophone and logistical support, Oregon Department of Fish and Wildlife for providing the vessel traffic data, John Calambokidis and Alie Perez (Cascadia Research Collective) for assistance with the photo- 
identification analysis, the OSU Marine Mammal Institute for logistical support, and Debbie Steel and Scott Baker (Cetacean Conservation and Genetic Laboratory/OSU) for assistance with the genetic analyses. We would also like to thank the Southwest Fisheries Science Center's Marine Mammal Genetics Program for providing data on the genetic sex of some of the individuals included in this study. This research was conducted under the NOAA/NMFS permits \#16011 and \#21678 issued to John Calambokidis. Drone operations were conducted by a Federal Aviation Authority (FAA) certified private pilot with a Part107 license or under a Certificate of Authorization (2016-WSA-101-COA).

\section{Author's contributions}

L.S.L. participated in fieldwork, conducted photo-identification and photogrammetry analyses, hormone assays, statistical analyses, and drafted the manuscript. J.H.H. led the acoustic components of the work, participated in fieldwork, contributed to interpretation of results, assisted with obtaining funding, and participated in study design. A.O. and A.S. conducted hormone validations and assisted with hormone assays. J.D.B. led whale photogrammetry method development. T.E.C. participated in fieldwork and contributed to field method developments. S.L.N. participated in fieldwork and participated in study design. S.E.L. oversaw hormone analyses and provided the assay kits. K.E.H. contributed to interpretation of results and participated in study design. J.H.H., A.O., A.S., J.D.B., T.E.C., S.L.N., S.E.L. and K.E.H. all critically revised the manuscript. L.G.T. envisioned the study, acquired funding for the research, designed and coordinated the project, lead the fieldwork, and drafted the manuscript. All authors give final approval for publication and agree to be held accountable for the work performed therein.

\section{References}

1. Ross, D. On ocean underwater ambient noise. Acoust. Bull, 18, 5-8 (1993).

2. Hildebrand, J. A. Anthropogenic and natural sources of ambient noise in the ocean. Mar. Ecol. Prog. Ser, 395, 5-20 (2009).

3. Chapman, N. R. \& Price, A. Low frequency deep ocean ambient noise trend in the Northeast Pacific Ocean. J. Acoust. Soc. Am, 129, EL161-EL165 (2011).

4. Weilgart, L. S. The impacts of anthropogenic ocean noise on cetaceans and implications for management. Can. J. Zool, 85, 1091-1116 (2007).

5. Hermannsen, L. et al. Recreational vessels without Automatic Identification System (AIS) dominate anthropogenic noise contributions to a shallow water soundscape. Sci. Rep, 9, 1-10 (2019).

6. Fewtrell, J. L. \& McCauley, R. Impact of air gun noise on the behaviour of marine fish and squid. Mar. Pollut. Bull, 64, 984-993 (2012).

7. Pine, M. K. et al. A Gulf in lockdown: How an enforced ban on recreational vessels increased dolphin and fish communication ranges. Glob. Chang. Biol, 00, 1-10 (2021).

8. Regnault, M. \& Lagardère, J. Effects of ambient noise on the metabolic level of Crangon crangon (Decapoda, Natantia). Mar. Ecol. Prog. Ser. Prog Ser, 11, 71-78 (1983). 
9. Pearson, W., Skalski, J., Sulkin, S. \& Malme, C. Effects of seismic energy releases on the survival and development of zoeal larvae of dungeness crab (Cancer magister). Mar. Environ. Res, 38, 93-113 (1994).

10. Kastak, D., Mulsow, J., Ghoul, A. \& Reichmuth, C. Noise-induced permanent threshold shift in a harbor seal. J. Acoust. Soc. Am, 2986, https://doi.org/10.1121/1.2932514 (2008).

11. Parks, S. E., Johnson, M., Nowacek, D. \& Tyack, P. L. Individual right whales call louder in increased environmental noise. Biol. Lett, 7, 33-35 (2011).

12. Bejder, L. et al. Decline in relative abundance of bottlenose dolphins exposed to long-term disturbance. Conserv. Biol, 20, 1791-1798 (2006).

13. Di lorio, L. \& Clark, C. W. Exposure to seismic survey alters blue whale acoustic communication. Biol. Lett, 6, 334-335 (2010).

14. Bas, A. A. et al. Marine vessels alter the behaviour of bottlenose dolphins Tursiops truncatus in the Istanbul Strait, Turkey. Endanger. Species Res, 34, 1-14 (2017).

15. Pirotta, E., Merchant, N. D., Thompson, P. M., Barton, T. R. \& Lusseau, D. Quantifying the effect of boat disturbance on bottlenose dolphin foraging activity. Biol. Conserv, 181, 82-89 (2015).

16. National Research Council. Marine Mammal Populations and Ocean Noise: Determining When Noise Causes Biologically Significant Effects. (2005).

17. Rolland, R. M. et al. Evidence that ship noise increases stress in right whales. Proc. R. Soc. B Biol. Sci. 279, 2363-2368(2012).

18. Yang, W. C. et al. Anthropogenic Sound Exposure-Induced Stress in Captive Dolphins and Implications for Cetacean Health. Front. Mar. Sci, 8, 1-8 (2021).

19. National Academies of Sciences Engineering and Medicine. Approaches to Understanding the Cumulative Effects of Stressors on Marine Mammals (The National Academies Press, 2017). Approaches to Understanding the Cumulative Effects of Stressors on Marine Mammals doi:10.17226/23479.

20. Pirotta, E. et al. Predicting the effects of human developments on individual dolphins to understand potential long-term population consequences. Proc. R. Soc. B Biol. Sci. 282(2015).

21. New, L. F. et al. Modelling the biological significance of behavioural change in coastal bottlenose dolphins in response to disturbance. Funct. Ecol, 27, 314-322 (2013).

22. New, L. F. et al. Using short-term measures of behaviour to estimate long-term fitness of southern elephant seals. Mar. Ecol. Prog. Ser, 496, 99-108 (2014).

23. Schick, R. S. et al. Estimating resource acquisition and at-sea body condition of a marine predator. J. Anim. Ecol, 82, 1300-1315 (2013).

24. Wikelski, M. \& Cooke, S. J. Conservation physiology. Trends Ecol. Evol, 21, 38-46 (2006).

25. Pirotta, E. et al. Understanding the population consequences of disturbance. Ecol. Evol, 8, 99349946 (2018). 
26. Le Boeuf, B. J., Perez-Cortes, M., Urbán, H., Mate, R. J., Ollervides, U. \& B. R. \& F. High gray whale mortality and low recruitment in 1999: Potential causes and implications (Eschrichtius robustus). J. Cetacean Res. Manag, 2, 85-99 (2000).

27. Moore, S. E. \& Huntington, H. P. Arctic Marine Mammals and Climate Change: Impacts and Resilience. Ecol. Appl, 18, S157-S165 (2008).

28. Soledade Lemos, L., Burnett, J. D., Chandler, T. E., Sumich, J. L. \& Torres, L. G. Intra- and inter-annual variation in gray whale body condition on a foraging ground. Ecosphere, 11, e03094 (2020).

29. Lemos, L. S. et al. Assessment of fecal steroid and thyroid hormone metabolites in eastern north Pacific gray whales. Conserv. Physiol, 8, coaa110 (2020).

30. Hunt, K. E., Rolland, R. M., Kraus, S. D. \& Wasser, S. K. Analysis of fecal glucocorticoids in the North Atlantic right whale (Eubalaena glacialis). Gen. Comp. Endocrinol, 148, 260-272 (2006).

31. Hunt, K. E. et al. Overcoming the challenges of studying conservation physiology in large whales: a review of available methods. Conserv. Physiol, 1, cot006- cot006 (2013).

32. Burek, K. A., Gulland, F. M. D. \& Hara, O. T. M. Effects of Climate Change on Arctic Marine Mammal Health Source.Ecol. Appl.18, (2018).

33. Read, A. J. The looming crisis: Interactions between marine mammals and fisheries. J. Mammal, $\mathbf{8 9}$, 541-548 (2008).

34. Sousa-Lima, R. S. \& Clark, C. W. Whale sound recording technology as a tool for assessing the effects of boat noise in a Brazilian marine park.Park Sci.26, (2009).

35. Tyack, P. L. Implications for Marine Mammals of Large-Scale Changes in the Marine Acoustic Environment. J. Mammal, 89, 549-558 (2018).

36. Valenzuela-Molina, M., Atkinson, S., Mashburn, K., Gendron, D. \& Brownell, R. L. Fecal steroid hormones reveal reproductive state in female blue whales sampled in the Gulf of California, Mexico. Gen. Comp. Endocrinol, 261, 127-135 (2018).

37. Selye, H. Stress and the general adaptation syndrome. Br. Med. J, https://doi.org/10.1136/bmj.1.4667.1383 (1950).

38. Romero, L. M. \& Wingfield, J. C. Tempests, poxes, predators, and people: Stress in wild animals and how they cope.Oxford series in behavioral neuroendocrinology614(2016).

39. Palme, R., Fischer, P., Schildorfer, H. \& Ismail, M. N. Excretion of infused 14C-steroid hormones via faeces and urine in domestic livestock. Anim. Reprod. Sci, 43, 43-63 (1996).

40. Wasser, S. K. et al. Non-invasive measurement of thyroid hormone in feces of a diverse array of avian and mammalian species. Gen. Comp. Endocrinol, 168, 1-7 (2010).

41. Creel, S. et al. Snowmobile activity and glucocorticoid stress responses in wolves and elk. Conserv. Biol, 16, 809-814 (2002).

42. Thiel, D., Jenni-Eiermann, S., Braunisch, V., Palme, R. \& Jenni, L. Ski tourism affects habitat use and evokes a physiological stress response in capercaillie Tetrao urogallus: A new methodological approach. J. Appl. Ecol, 45, 845-853 (2008). 
43. Slabbekoorn, H., McGee, J. \& Walsh, E. J. Effects of Man-Made Sound on Terrestrial Mammals. in Effects of anthropogenic noise on animals 243-276(Springer, 2018). doi:10.1007/978-1-4939-85746_9.

44. Palme, R. Non-invasive measurement of glucocorticoids: Advances and problems. Physiol. Behav, 199, 229-243 (2019).

45. Goymann, W. On the use of non-invasive hormone research in uncontrolled, natural environments: The problem with sex, diet, metabolic rate and the individual. Methods Ecol. Evol, 3, 757-765 (2012).

46. Lemos, L. S. et al. Stressed and slim or relaxed and chubby? A simultaneous assessment of gray whale body condition and hormone variability. Mar. Mammal Sci. (In Press.

47. Torres, L. G., Nieukirk, S. L., Lemos, L. \& Chandler, T. E. Drone up! Quantifying whale behavior from a new perspective improves observational capacity. Front. Mar. Sci, 5, 1-14 (2018).

48. Vu, E. T., Clark, C., Catelani, K., Kellar, N. M. \& Calambokidis, J. Seasonal blubber testosterone concentrations of male humpback whales (Megaptera novaeangliae). Mar. Mammal Sci, 31, 12581264 (2015).

49. Trumble, S. J., Robinson, E. M., Berman-Kowalewski, M., Potter, C. W. \& Usenko, S. Blue whale earplug reveals lifetime contaminant exposure and hormone profiles. Proc. Natl. Acad. Sci. U. S. A. 110, 16922-16926(2013).

50. Barrett-Lennard, L. G., Matkin, C. O., Durban, J. W., Saulitis, E. L. \& Ellifrit, D. Predation on gray whales and prolonged feeding on submerged carcasses by transient killer whales at Unimak Island, Alaska. Mar. Ecol. Prog. Ser, 421, 229-241 (2011).

51. Dailey, M. D., Gulland, F. M. D., Lowenstine, L. J., Silvagni, P. \& Howard, D. Prey, parasites and pathology associated with the mortality of a juvenile gray whale (Eschrichtius robustus) stranded along the northern California coast. Dis. Aquat. Organ, 42, 111-117 (2000).

52. Sullivan, F. A. \& Torres, L. G. Assessment of vessel disturbance to gray whales to inform sustainable ecotourism. J. Wildl. Manage, 82, 896-905 (2018).

53. Shannon, G. et al. A synthesis of two decades of research documenting the effects of noise on wildlife. Biol. Rev, 91, 982-1005 (2016).

54. Burnett, J. D. et al. Estimating morphometric attributes of baleen whales with photogrammetry from small UASs: A case study with blue and gray whales. Mar. Mammal Sci, 35, 108-139 (2019).

55. R Core Team. R: A language and environment for statistical computing. (2019).

56. Ayres, K. L. et al. Distinguishing the impacts of inadequate prey and vessel traffic on an endangered killer whale (Orcinus orca) population. PLoS One, 7, e36842 (2012).

57. Wood, M. D., Beresford, N. A. \& Copplestone, D. Limit of detection values in data analysis: Do they matter?, 46, 85-90 (2011).

58. Haxel, J. H., Dziak, R. P. \& Matsumoto, H. Observations of shallow water marine ambient sound: The low frequency underwater soundscape of the central Oregon coast. J. Acoust. Soc. Am, 133, 25862596 (2013). 
59. Parsons, M. J. G., Erbe, C., Meekan, M. G. \& Parsons, S. K. A Review and Meta-Analysis of Underwater Noise Radiated by Small (<25 m Length) Vessels. J. Mar. Sci. Eng, 9, 827 (2021).

60. Hildebrand, J. A., Frasier, K. E., Baumann-Pickering, S. \& Wiggins, S. M. An empirical model for windgenerated ocean noise. J. Acoust. Soc. Am, 149, 4516-4533 (2021).

61. Dahlheim, M. \& Castellote, M. Changes in the acoustic behavior of gray whales Eschrichtius robustus in response to noise. Endanger. Species Res, 31, 227-242 (2016).

62. Guazzo, R. A. et al. Migratory behavior of eastern North Pacific gray whales tracked using a hydrophone array. PLoS One, 12, e0185585 (2017).

63. Guazzo, R. A. et al. Migrating eastern North Pacific gray whale call and blow rates estimated from acoustic recordings, infrared camera video, and visual sightings. Sci. Rep, 9, 12617 (2019).

64. Knudsen, V. O., Alford, R. S. \& Emling, J. W. Underwater Ambient Noise. J. Mar. Res, 7, 410-429 (1948).

65. Rolland, R. M., Hunt, K. E., Kraus, S. D. \& Wasser, S. K. Assessing reproductive status of right whales (Eubalaena glacialis) using fecal hormone metabolites. Gen. Comp. Endocrinol, 142, 308-317 (2005).

66. Bates, D., Mächler, M., Bolker, B. M. \& Walker, S. C. Fitting linear mixed-effects models using Ime4.J. Stat. Softw.67, (2015).

67. Wasser, S. K. et al. A generalized fecal glucocorticoid assay for use in a diverse array of nondomestic mammalian and avian species. Gen. Comp. Endocrinol, 120, 260-275 (2000).

68. Hunt, K. E., Trites, A. W. \& Wasser, S. K. Validation of a fecal glucocorticoid assay for Steller sea lions (Eumetopias jubatus). Physiol. Behav, 80, 595-601 (2004).

69. Burnham, K. P., Anderson, D. R. \& Huyvaert, K. P. Aic model selection and multimodel inference in behavioral ecology: Some background, observations, and comparisons.Behav. Ecol. Sociobiol.2335(2011).

70. Nakagawa, S. \& Schielzeth, H. A general and simple method for obtaining R2 from generalized linear mixed-effects models. Methods Ecol. Evol, 4, 133-142 (2013).

71. Barton, K. \& MuMIn Multi-Model Inference. R Packag. version 1.43.17(2020).

72. Kuznetsova, A., Brockhoff, P. B. \& Christensen, R. H. B. ImerTest Package: Tests in Linear Mixed Effects Models.J. Stat. Softw.82, (2017).

73. Lemos, L. S. et al. Data from: Sounds of stress: Assessment of relationships between ambient noise, vessel traffic, and gray whale stress hormone. Sci. Rep. Dryad, Dataset(2021) doi:https://doi.org/10.5061/dryad.n5tb2rbvn.

\section{Figures}




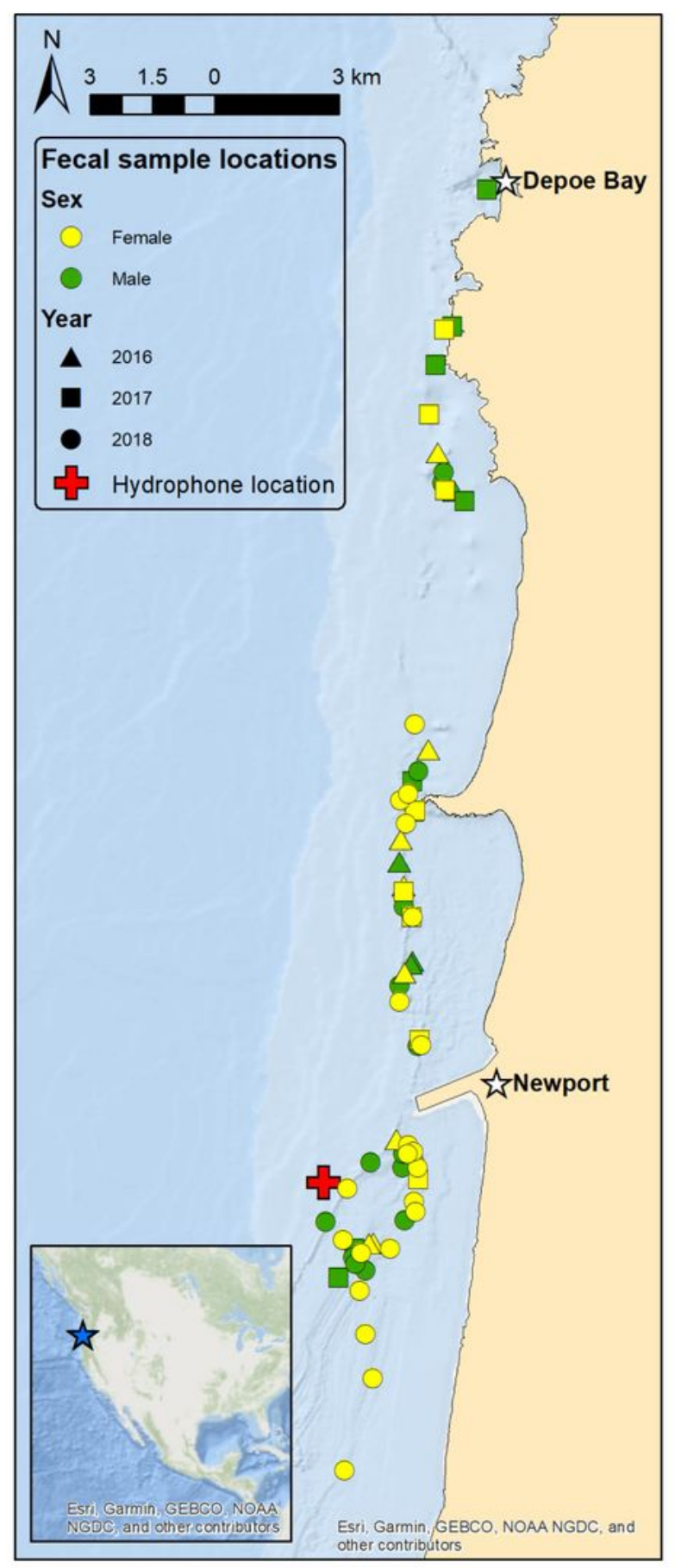

\section{Figure 1}

Location of field site off the central Oregon, USA coast (blue star on inset map), hydrophone deployment site (red cross), and gray whale fecal sample collections symbolized by color and shape to represent sex and year. The ports of Newport and Depoe Bay are represented by white stars. The Newport white star is also representing the anemometer station (NPOW3) from which the wind speed data were retrieved from. 


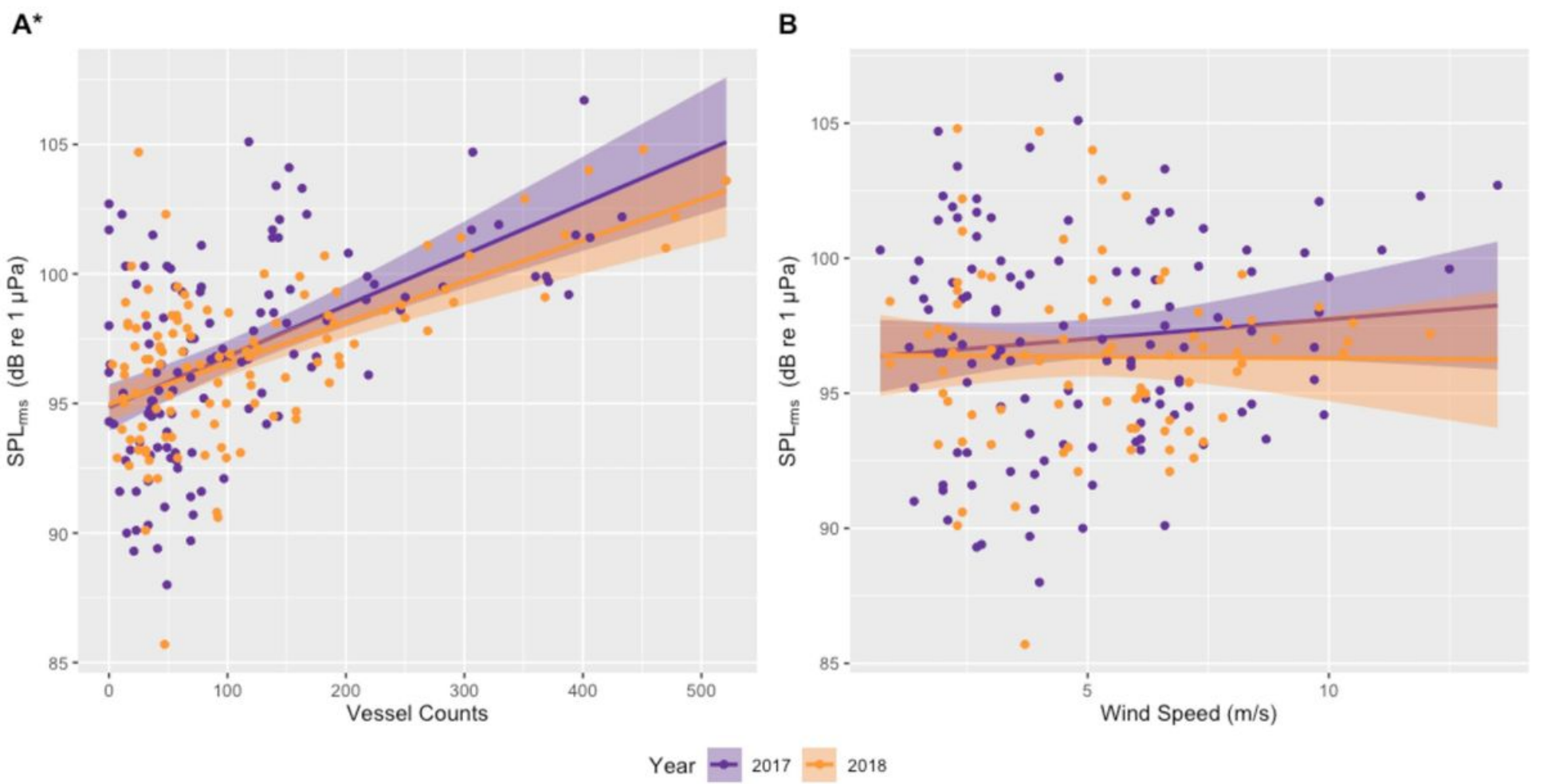

Figure 2

Linear correlations between noise levels (daily median root mean square [rms] sound pressure level [SPL] in dB [re $1 \mu \mathrm{Pa} @ 1 \mathrm{~m}] ; 50 \mathrm{~Hz}-1,000 \mathrm{~Hz}$ ) recorded on a hydrophone deployed outside the Newport harbor entrance during June to October of 2017 and 2018 and (A) vessel counts in Newport and Depoe Bay, Oregon, USA, and (B) daily median wind speed $(\mathrm{m} / \mathrm{s})$ from an anemometer station located on South Beach, Newport, Oregon, USA (station NWPO3). Asterisk indicates significant correlations between the variables in both years. 


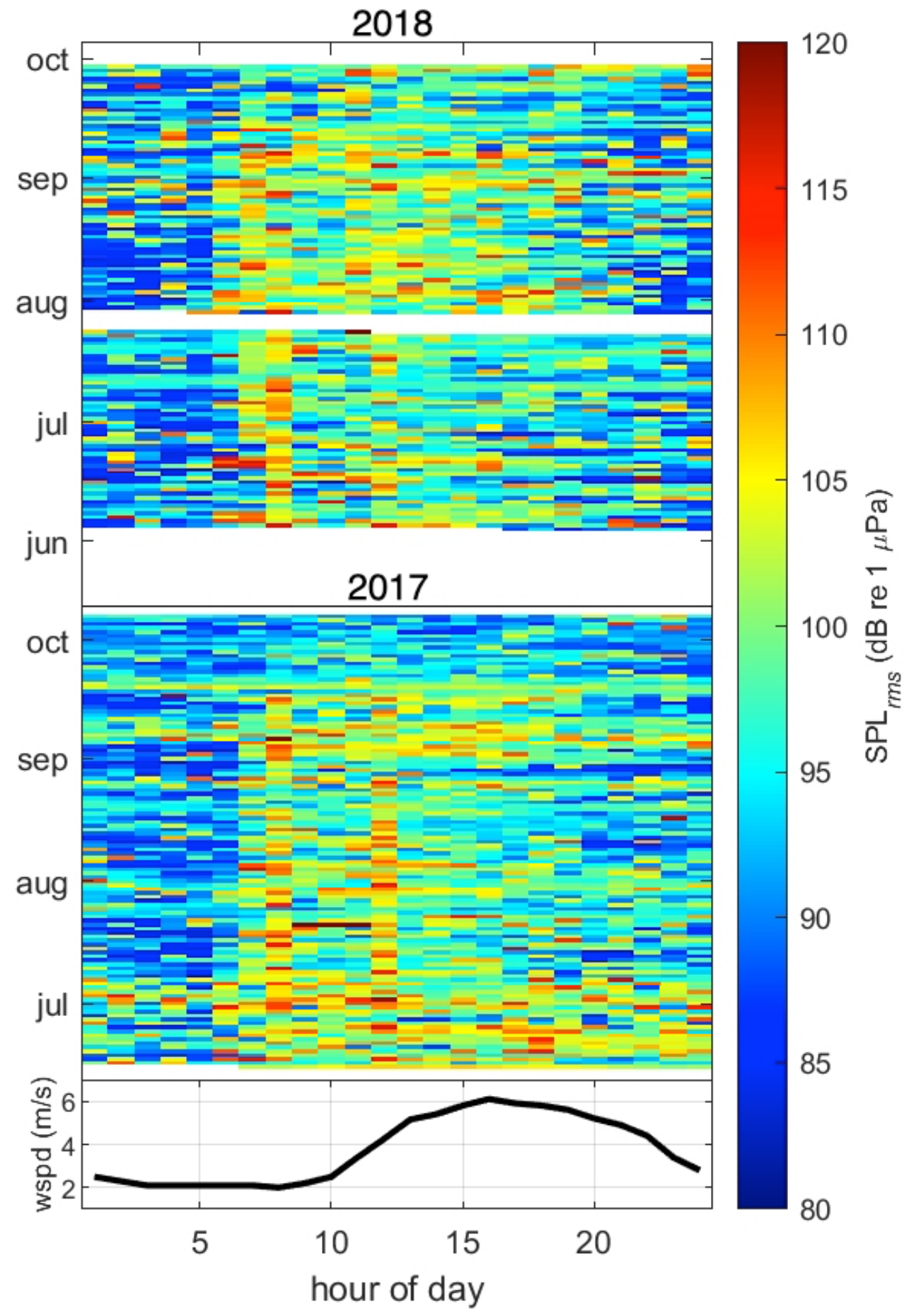

\section{Figure 3}

Median noise levels (root mean square sound pressure levels (SPLrms)) for each hour of each day recorded on a hydrophone $(50 \mathrm{~Hz}-10,000 \mathrm{~Hz})$ deployed outside the Newport harbor entrance during June to October of 2017 (middle plot) and 2018 (upper plot), and median hourly wind speed (lower plot) from an anemometer station located on South Beach, Newport, Oregon, USA (station NWPO3) over the same time period. 

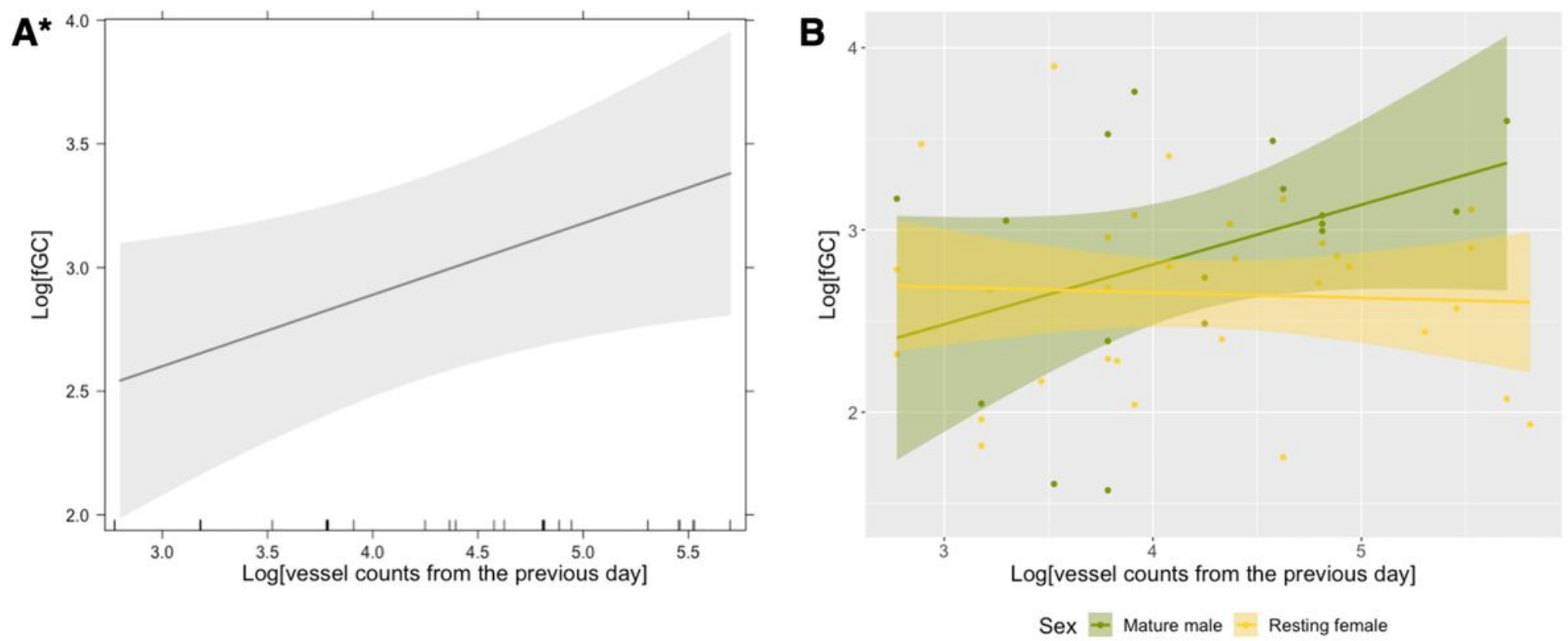

\section{Figure 4}

(A) The effect of vessel count in Newport and Depoe Bay (Oregon, USA) on the day previous to fecal sample collection on gray whale fecal glucocorticoid metabolite (fGC) concentrations, derived from linear mixed model results with whale identification, day of year, and month as random effects (Table 2; Model 2). (B) Linear correlations between fGC concentrations and vessel count, partitioned by sex. Data collected between May and October of 2016, 2017 and 2018. Asterisk indicates significant correlations between the variables in $(A)$. 


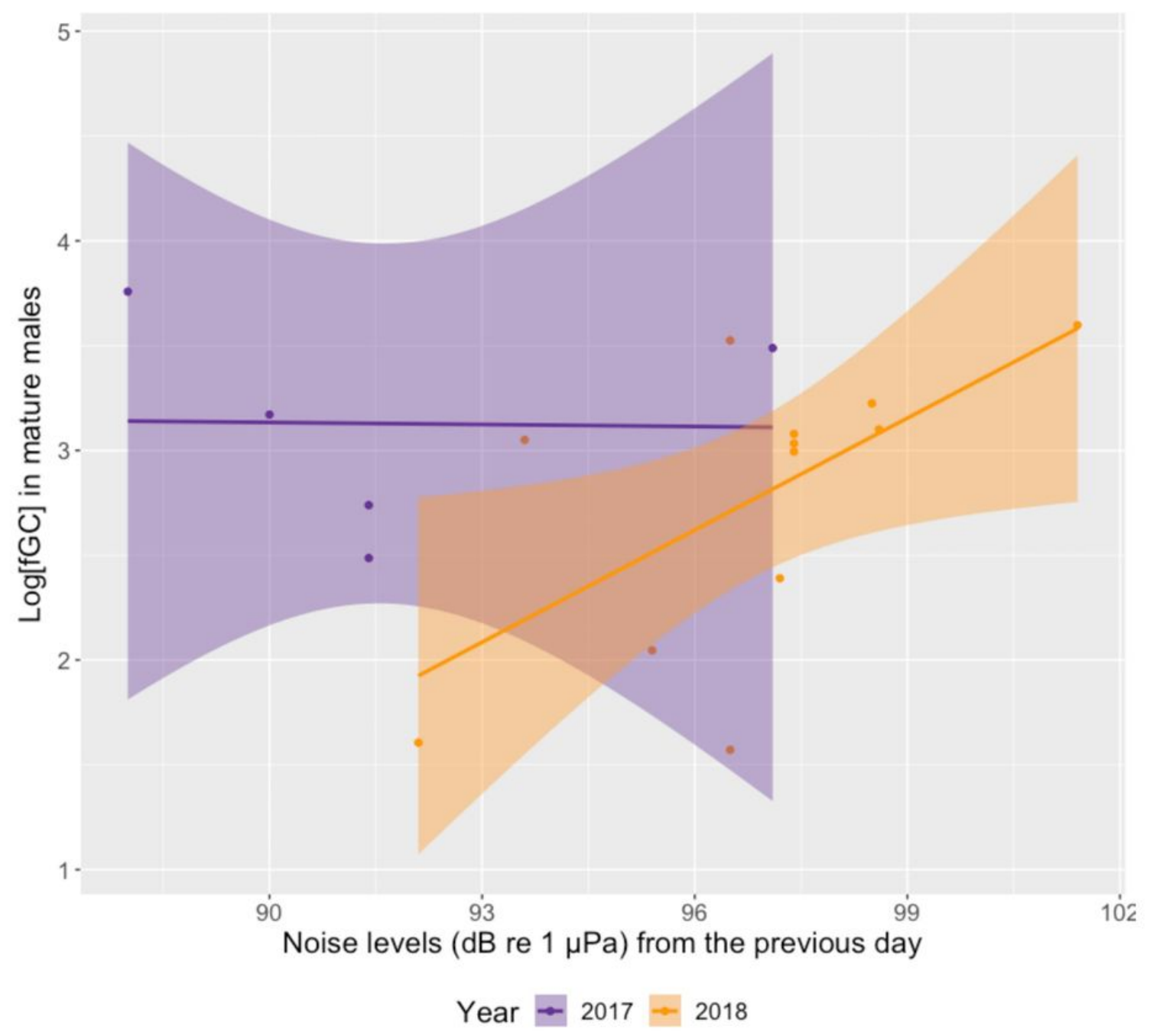

\section{Figure 5}

Linear correlation between fecal glucocorticoid metabolites (fGC) in mature male gray whales and noise levels (daily median SPLrms, in dB [re $1 \mu \mathrm{Pa} @ 1 \mathrm{~m}] ; 50 \mathrm{~Hz}-1,000 \mathrm{~Hz}$ ) recorded on a hydrophone deployed outside the Newport harbor entrance during June to October of 2017 and 2018. Gray whale mature males only displayed a significant positive correlation between variables in 2018.

\section{Supplementary Files}

This is a list of supplementary files associated with this preprint. Click to download.

- SupplementaryMaterial.docx 